\title{
ASYMPTOTIC STABILITY AND INTEGRAL INEQUALITIES FOR SOLUTIONS OF LINEAR SYSTEMS ON RADON-NIKODÝM SPACES
}

\author{
Constantin Buşe, Constantin P. Niculescu And Josip PeČarić
}

Abstract. We consider the mild solution $u_{f}(\cdot, 0)$ of a well-posed nonhomogeneous Cauchy problem

$$
\left\{\begin{aligned}
\dot{u}(t) & =A(t) u(t)+f(t), \quad t \geqslant 0 \\
u(0) & =0
\end{aligned}\right.
$$

on a Radon-Nikodým space $X$, where $A(\cdot)$ is a linear operator-valued function. Under certain additional conditions we will prove that if the homogeneous system

$$
\dot{u}(t)=A(t) u(t), \quad t \geqslant 0
$$

is exponentially stable, then for each function $f$ belonging to the Sobolev space $W_{p 1}^{0}\left(\mathbb{R}_{+}, X\right)$, $1 \leqslant p<\infty$, the solution $u_{f}(\cdot, 0)$ lies in the same space. The converse statement is more subtle, but it certainly works in the autonomous case. Integral inequalities of Landau type for the evolution semigroup associated with the system $(A(t))$ on the space $W_{p 1}^{0}\left(\mathbb{R}_{+}, X\right)$ are also derived.

Mathematics subject classification (2000): 47A10, 47A30, 46N20, 35B35, 26D10.

Key words and phrases: Evolution family, exponential stability, differential inequalities.

\section{REFERENCES}

[1] C. BUŞE, D. BARBU, Some remarks about the Perron conditions for $C_{0}$-semigroups, Ann. Univ. din Timişoara, 35, 1 (1997), 3-8.

[2] C. Chicone, Yu. LatushKin, Evolution Semigroups in Dynamical Systems and Differential Equations, Math. Surv. and Monographs, 70, Amer. Math. Soc., R. I., 1999.

[3] S. Clark, Yu. Latushkin, S. Montgomery-SMith and T. Randolph, Stability radius and internal stability versus external stability in Banach spaces: An evolution semigroup approach, SIAM J. Control and Optimization, 38, (2000), 1757-1793.

[4] P. CANNARSA, G. DA PRATO AND J.P. ZolÉsio, The damped wawe equation in a noncylindrical domain, J. Differential Equations, 85, (1990), 1-14.

[5] Ju. L. DaleckiJ, M. G. KreIN, Stability of Solutions of Differential Equations in Banach Spaces, Transl. of Math. Monogr., 4, Amer. Math. Soc., Providence, R.I., 1974.

[6] Diestel J., Uhl J. J., Vector measures, Math. Surveys, no. 5, Amer. Math. Soc., Providence, R.I., 1977.

[7] R. R. Kallman, G. C. Rota, On the inequality $\left\|f^{\prime}\right\| \leqslant 4\|f\|\left\|f^{\prime \prime} y\right\|$, Inequalities II, O. Shisha Editor. Acadmic Press, New-York, 1970, pp.187-192.

[8] Yu. LATUSHKIn, S. MONTGOMERY-SMITH AND T. RANDOLPH, Evolution semigroups and robust stability of evolution operators on Banach spaces, preprint.

[9] J. L. MASSERA, J. J. SCHÄFFER, Linear Differential Equations and Function Spaces, Pure and Applied Math., 21, Academic Press, New-York, London, 1966.

[10] NGUYEN VAN Minh, F. RÄBIGER AND R. SCHNAUBELT, Exponential stability, exponential expansiveness, exponential dichotomy of evolution equations on the half line, Integral Equations Operator Theory, 32, (1998), 332-353. 
[11] R. Nagel (ED.), One-Parameter Semigroups of Positive Operators, Springer-Verlag, Lect. Notes in Math. 1184, (1986).

[12] J. M. A. M VAn NeERVEn, Lower semicontinuity and the theorem of Datko and Pazy, Integr. Oper. Theory, 42, (2002), 482-492.

[13] Vu Quoc Phong, On stability of $C_{0}$-semigroups, Proc. Amer. Math. Soc., 129, 10 (2002), 2871-2879.

[14] M. REGHIŞ, C. Buşe, On the Perron-Bellman theorem for $C_{0}$-semigroups and periodic evolutionary processes in Banach spaces, Italian Journal of Pure and Applied Mathematics, 4, (1988), 155-166.

[15] F. RÄBIGER, R. SCHNAUBELT, A spectral characterization of exponentially dichotomic and hyperbolic evolution families, Tübinger Berichte zur Funktionalanalysis, 3, (1994), 204-221.

[16] F. RÄBIGER, R. SCHNAUBELT, Absorption evolution families and exponential stability of nonautonomous difussion equations, Differential Integral Equations 12, (1999), 41-65.

[17] R. SCHNAUBELT, Well posedness and asymptotic behaviour of non-autonomous linear evolution equations, Evolution equations, semigroups and functional analysis (Milano-2000), Prog. Nonlinear Differential Equations Appl., Birkhäuser Basel, (2002), 318-338. 